http://jmscr.igmpublication.org/home/ ISSN (e)-2347-176x ISSN (p) 2455-0450 crossref DOI: https://dx.doi.org/10.18535/jmscr/v7i10.134

Journal Of Medical Science And Clinical Research

\title{
Efficacy of Electro dissection Technique using Bipolar Diathermy in Tonsillectomy
}

Authors

\author{
Dr Ruta Shanmugam, Dr Rajesh Kumar², Dr Balaji Swaminathan ${ }^{3}$, \\ Dr V.U.Shanmugam ${ }^{4}$, Dr Prem Nivas ${ }^{5}$ \\ ${ }^{1}$ Professor, Dept of ENT, RMMCH, Annamalai University, Chidambaram \\ ${ }^{2}$ Post Graduate, Dept of ENT, RMMCH, Annamalai University, Chidambaram. \\ ${ }^{3} \mathrm{HOD}$, Dept of ENT, RMMCH, Annamalai University, Chidambaram \\ ${ }^{4}$ Professor, Dept of ENT, RMMCH, Annamalai University, Chidambaram \\ ${ }^{5}$ Assistant Professor, Dept of ENT, RMMCH, Annamalai University, Chidambaram.
}

\begin{abstract}
Conventional tonsillectomy and bipolar tonsillectomy are the common techniques used in paediatric population with different indications. Our purpose in this study is to offer a comparative evaluation of the intraoperative and postoperative effects of these techniques in paediatric patients.
\end{abstract}

Aim: To study the effectiveness of electro dissection technique using bipolar diathermy in children undergoing tonsillectomy, interms of intraoperative time, blood loss, post operative pain and post operative complications like reactionary and secondary haemorrhage.

Materials and Methods: Study is based on the analysis of 50 patients who underwent tonsillectomy between October 2017 to September 2019 at Rajah Muthiah Medical College Hospital, Chidambaram. 50 children were divided into Group A and Group B containing 25 children in each group. The Tonsillectomy was performed under General Anaesthesia. Group A children underwent tonsillectomy by Dissection and Snare method and Group B children will be underwent tonsillectomy by Bipolar Diathermy method.

Results: The total mean operative time for bipolar diathermy method was $45.12 \pm 9.42$ minutes and the mean operative time for the dissection and snare was 69.64 minutes \pm 23.31 minutes. The mean intraoperative blood loss for dissection and snare was $59.60 \pm 14.02 \mathrm{ml}$ and for bipolar diathermy method, the mean intra operative blood loss was $39.36 \pm 6.39 \mathrm{ml}$. The post operative pain assessed using VAS showed that the pain was more in the Bipolar Group (Group B) from Day 0 to Day 5. However, there was not much difference in post operative pain in the 2 groups on Day6, Day7\&Day14. In our study we encountered 1 primary haemorrhage in the dissection and snare method and none on bipolar diathermy method. There were 1 secondary haemorrhage in dissection and snare method and there was 4 secondary haemorrhage in bipolar diathermy method.

Conclusion: Bipolar electrocautery tonsillectomy is a favourable technique in view of ease of the procedure, lesser operative time and less intraoperative blood loss. However dissection and snare tonsillectomy, it is a time tested technique with less post operative pain and morbidity, hence more acceptable to the patient.

Keywords: Tonsillectomy, dissection and snare, bipolar diathermy. 


\section{Introduction}

Tonsillectomy is one of the oldest and most frequent procedures of the ear, nose and throat surgery. It was not until the beginning of the twentieth century that Worthington and Waugh described the modern technique of tonsillectomy by dissection. Cautery ${ }^{2}$ use in tonsillectomy was first defined in 1962. Further, Andrea defined the first microsurgical bipolar cautery technique ${ }^{3}$ in 1993. Tonsillectomy is performed by a variety of techniques. These techniques have evolved over the years aiming to make the procedure safe and decrease the surgical time, intra operative blood loss, post operative morbidity and complications. Despite the developments in techniques and technology, tonsillectomy still carries a relatively high risk of morbidity. Conventional tonsillectomy and bipolar tonsillectomy ${ }^{4}$ are the common techniques used in paediatric population with different indications ${ }^{9}$. Our purpose in this study is to offer a comparative evaluation of the intraoperative and postoperative effects of these techniques in paediatric patients ${ }^{1}$.

\section{Materials and Methods}

Interventional study of tonsillectomy done at Rajah Muthiah Medical College Hospital, Chidambaram. Study was conducted among the children who underwent Tonsillectomy at Rajah Muthiah Medical College Hospital, Chidambaram during October 2017 to September 2019.

\section{Inclusion Criteria}

1. Children aged 5 to 14 years of either sex with recurrent/chronic tonsillitis.

2. Hypertrophied tonsils with obstructive symptoms such as snoring, apnoea or dysphagia.

\section{Exclusion Criteria}

1. All adults above the age of 14 years.

2. Patients undergoing tonsillectomy for glossopharyngeal neurectomy, styloid process removal.

3. Patients suffering from peritonsillar abscess within six weeks pre-operatively.
4. Patients with chronic illnesses eg. diabetes, symptomatic heart disease, bleeding and clotting disorders, immunodeficiency, and malignancy.

\section{Method of Study}

After obtaining the clearance from ethical committee, study was started in Rajah Muthiah Medical College Hospital. 50 children were enrolled in the study and were divided into Group A and Group B containing 25 children in each group. Complete history taking, clinical examination and blood investigations was carried out in all the children. Tonsillectomy was performed under General Anaesthesia. Group A children underwent tonsillectomy by Dissection and Snare method and Group B children underwent tonsillectomy by Bipolar Diathermy method.

Operative time was recorded from the insertion of Boyle Davis mouth gag to its removal.

Amount of intra operative blood loss was measured by finding the difference in the weights of the pre operative cotton swabs (a) and post operative cotton swabs(b) and the resulting total obtained $(1 \mathrm{gm}=1 \mathrm{ml})$ was added to the difference between the volume of pre operative saline in the irrigation bowl(c) and the volume of fluid in the suction bottle(d) post operatively. The following formula was used.

Total intra operative blood loss

$$
(\mathrm{ml})=(\mathrm{b}-\mathrm{a})+(\mathrm{d}-\mathrm{c}) \text {. }
$$

Post operative pain was recorded using Visual Analogue scale. Children were shown the Visual Analogue Scale and were asked to rate from 010. A higher score indicates greater pain intensity. The postoperative pain intensity was categorised as none, mild, moderate, or severe. no pain (0), mild pain (1-3), moderate pain (4$7)$, and severe pain $(8-10)$. The Visual Analogue Scale was used on the day of surgery and every 24 hours till the time of discharge and on $14^{\text {th }}$ post operative day.

Complications like reactionary haemorrhage and secondary haemorrhage were looked for till the 
day of discharge and on the $14^{\text {th }}$ post operative day.

\section{Observation and Results}

There were 32 children (64\%) in the age group of 5-10 years and 18 children (36\%) in the age group of 11-14 years. The mean age in our study was
$9.5 \pm 2.38$ years.

The total mean operative time for bipolar diathermy method was $45.12 \pm 9.42$ minutes which was lesser than the mean operative time for the dissection and snare method which was 69.64 minutes \pm 23.31 minutes (Figure 1). This is statistically significant $\mathrm{p}$ value $<0.001$ (Table 1 ).

Table 1: Comparison of mean operative time (in mins) between two group ( $\mathrm{N}=50)$

\begin{tabular}{|c|c|c|c|}
\hline \multirow[b]{2}{*}{ Parameter } & \multicolumn{2}{|c|}{ Group } & \multirow[b]{2}{*}{$\underset{\text { test } P \text { value }}{\text { Unpaired }}$} \\
\hline & $\begin{array}{c}\text { A } \\
\text { Snare } \\
(\mathbf{N}=\mathbf{2 5})\end{array}$ & $\begin{array}{c}\text { B } \\
\text { Bipolar } \\
(\mathbf{N}=25)\end{array}$ & \\
\hline Operative time (in mins) (Mean \pm STD) & $69.64 \pm 23.31$ & $45.12 \pm 9.42$ & $<0.001$ \\
\hline
\end{tabular}

Figure 1: Bar chart of comparison of mean operative time (in mins) between group ( $\mathrm{N}=50)$

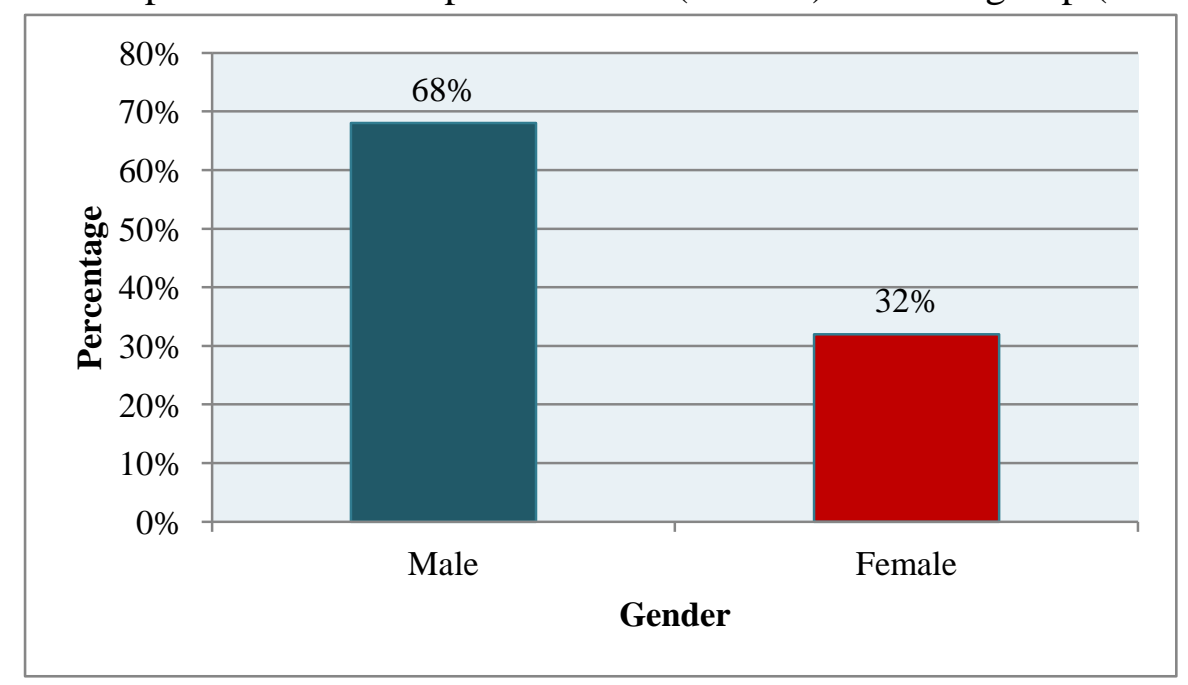

The mean intraoperative blood loss for dissection and snare was $59.60 \pm 14.02 \mathrm{ml}$ and for bipolar diathermy method, the mean intra operative blood loss was $39.36 \pm 6.39 \mathrm{ml}$ (Figure 2). This shows that the amount of blood loss in bipolar diathermy group (Group B) was lesser than the intra operative blood loss in dissection and snare (Group A). The $\mathrm{p}$ value was less than 0.001(Table 2) and it is statistically significant.

Table 2: Comparison of mean intra operative blood loss (in $\mathrm{ml}$ ) between two group $(\mathrm{N}=50)$

\begin{tabular}{|l|c|c|c|}
\hline \multirow{2}{*}{ Parameter } & \multicolumn{2}{|c|}{ Group } & Unpaired t test \\
\cline { 2 - 4 } & \multicolumn{1}{|c|}{$\begin{array}{c}\text { B } \\
\text { Pnare } \\
(\mathbf{N}=\mathbf{2 5})\end{array}$} & $\begin{array}{c}\text { B } \\
\text { Bipolar } \\
(\mathbf{N}=25)\end{array}$ \\
\hline $\begin{array}{l}\text { Intra operative blood loss (in } \mathrm{ml}) \\
\text { (Mean } \pm \text { STD) }\end{array}$ & $59.60 \pm 14.02$ & $39.36 \pm 6.39$ & $<0.001$ \\
\hline
\end{tabular}


Figure 2: Bar chart of comparison of mean operative blood loss (in ml) between group ( $\mathrm{N}=50)$

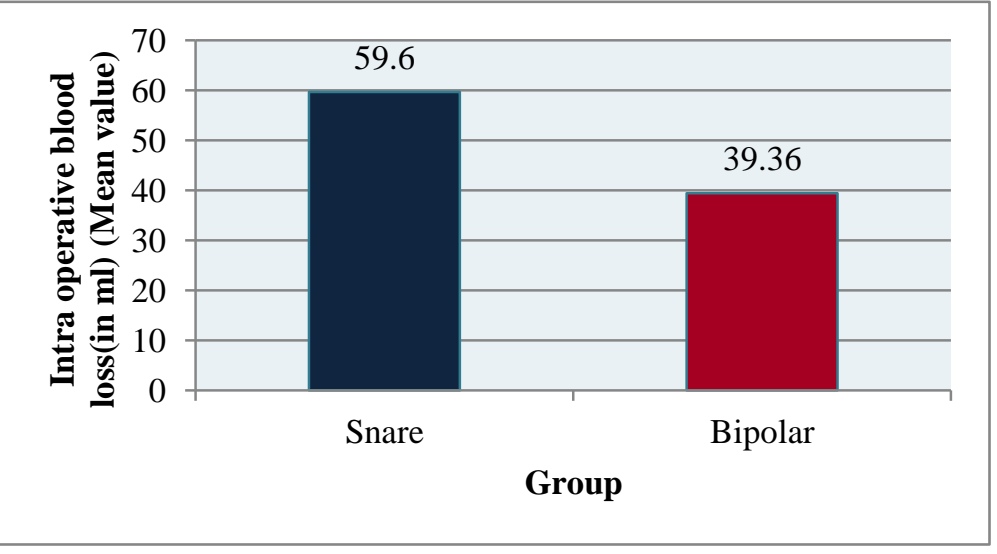

The post operative pain assessed using VAS showed that the pain was more in the Bipolar Group (Group B) from Day 0 to Day 5.This was statistically significant $\mathrm{P}$ value $<0.001$.However, There was not much difference in post operative pain in the 2 groups on Day6, Day7 \& Day14.

Table 3: Comparison of mean post operative pain (VAS) between two groups $(\mathrm{N}=50)$

\begin{tabular}{|l|c|c|c|}
\hline \multirow{2}{*}{ Post Operative Pain(VAS) } & \multicolumn{2}{|c|}{ Group } & \multirow{2}{*}{$\begin{array}{c}\text { Unpaired t } \\
\text { test P value }\end{array}$} \\
\cline { 2 - 3 } & $\begin{array}{c}\text { A } \\
\text { Snare } \\
(\mathbf{N = 2 5})\end{array}$ & $\begin{array}{c}\text { B } \\
\text { Bipolar } \\
(\mathbf{N = 2 5})\end{array}$ & \\
\hline Day 0 (Mean \pm STD) & $8.48 \pm 0.51$ & $9 \pm 0$ & $<0.001$ \\
\hline Day 1 (Mean \pm STD) & $7.88 \pm 0.33$ & $8.76 \pm 0.44$ & $<0.001$ \\
\hline Day 2 (Mean \pm STD) & $6.40 \pm 0.76$ & $7.64 \pm 0.49$ & $<0.001$ \\
\hline Day 3 (Mean \pm STD) & $4.72 \pm 0.89$ & $6.48 \pm 0.51$ & $<0.001$ \\
\hline Day 4 (Mean \pm STD) & $3.40 \pm 0.76$ & $5.12 \pm 0.73$ & $<0.001$ \\
\hline Day 5 (Mean \pm STD) & $2.36 \pm 0.49$ & $2.96 \pm 0.79$ & $<0.001$ \\
\hline Day 6 (Mean \pm STD) & $0.88 \pm 0.60$ & $1.24 \pm 0.44$ & 0.002 \\
\hline Day 7 (Mean \pm STD) & $0 \pm 0$ & $0 \pm 0$ & - \\
\hline Day 14 (Mean \pm STD) & $0 \pm 0$ & $0 \pm 0$ & - \\
\hline
\end{tabular}

Figure 3: Trend line diagram of comparison of mean post operative pain (VAS) different follow up time period between two group $(\mathrm{N}=50)$

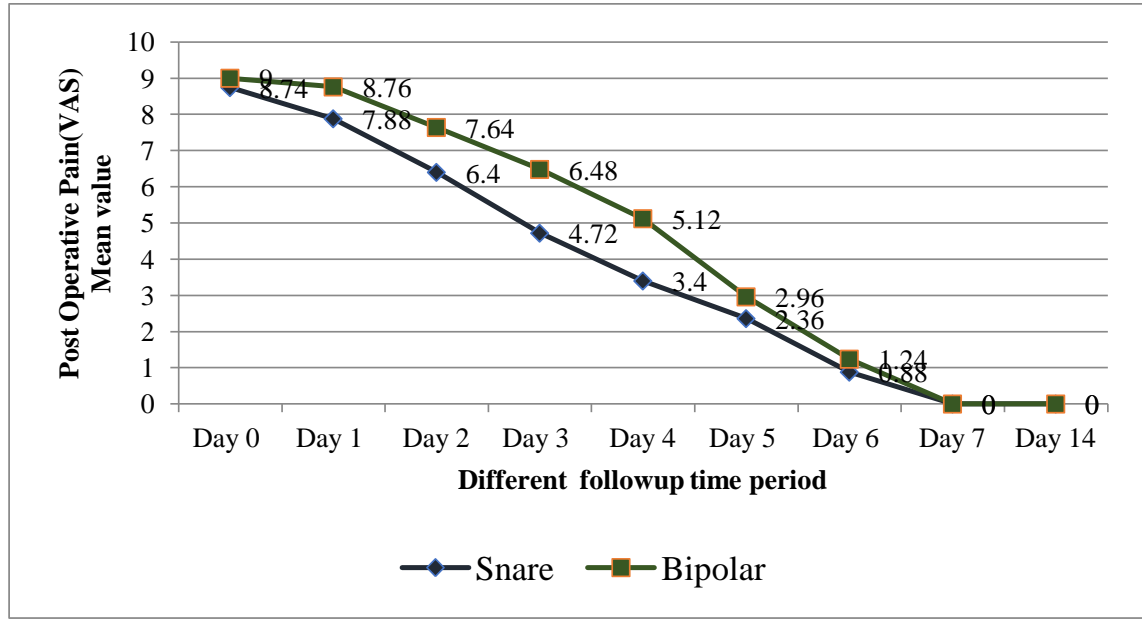

In our study we encountered 1 primary $(4 \%)$ haemorrhage in the dissection and snare method and none in bipolar diathermy method.

There was 1 secondary (4\%) haemorrhage in dissection and snare method and there were 4 secondary haemorrhage $(16 \%)$ in bipolar diathermy (Table 3).

The incidence of secondary haemorrhage was 
more in bipolar diathermy method compared to dissection and snare method in our study.
However it was stastically not significant ( $\mathrm{P}$ value $0.236)$.

Table 4: Comparison of post operative complications between two group $(\mathrm{N}=50)$

\begin{tabular}{|l|c|c|c|}
\hline \multirow{2}{*}{$\begin{array}{l}\text { Post operative } \\
\text { complications }\end{array}$} & $\begin{array}{c}\text { A } \\
\text { Snare } \\
(\mathbf{N = 2 5 )}\end{array}$ & $\begin{array}{c}\text { Group } \\
\text { Bipolar } \\
(\mathbf{N = 2 5 )}\end{array}$ & Total \\
\hline Secondary haemorrhage & 1 & 4 & 5 \\
\hline Percentage & $4 \%$ & $16 \%$ & $83.3 \%$ \\
\hline Primary haemorrhage & 1 & 0 & 1 \\
\hline Percentage & $4 \%$ & $0 \%$ & $2 \%$ \\
\hline No haemorrhage & 23 & 21 & 84 \\
\hline Percentage & $92 \%$ & 4 & 50 \\
\hline Total & 2 & 2.891 & \\
\hline Chi square & \multicolumn{3}{|c|}{} \\
\hline P value & \multicolumn{3}{|c|}{0.236} \\
\hline
\end{tabular}

Figure 4: Cluster bar chart of comparison of post operative complications with group $(\mathrm{N}=50)$

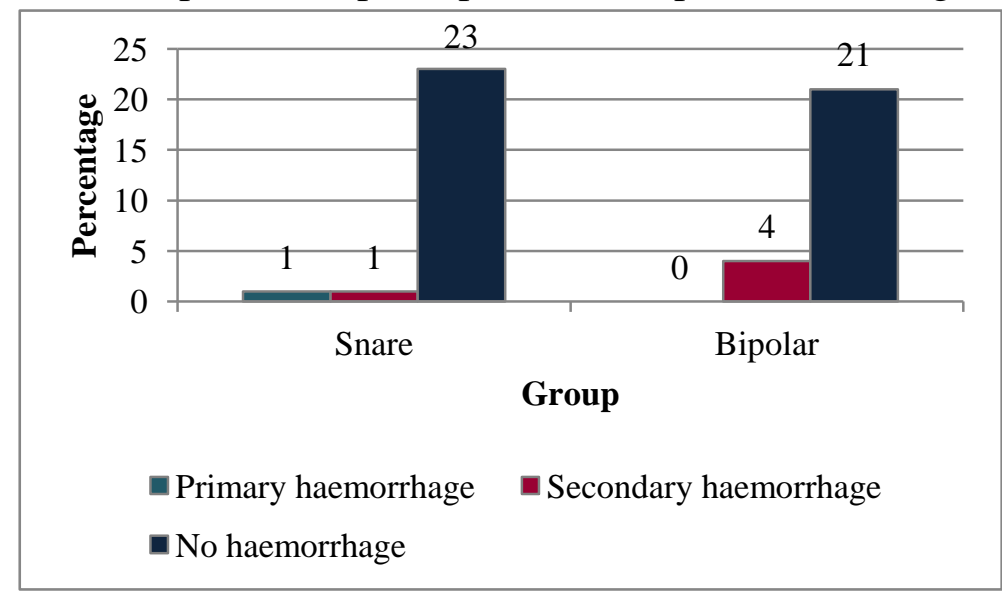

\section{Discussion}

\section{Operative Time}

The total mean operative time for bipolar diathermy method was $45.12 \pm 9.42$ minutes which was lesser than the mean operative time for the dissection and snare which was 69.64 minutes \pm 23.31 minutes. This is statistically significant $p$ value $<0.001$.

Our results were similar to the study performed by Guclu kaan beriat et $\mathrm{al}^{1}$, they studied results in 31 children who underwent tonsillectomy by bipolar cautery and compared with 45 children who underwent cold dissection tonsillectomy and reported mean operation time for dissection and snare was 29.53 minutes and for the bipolar diathermy was 20.33 minutes.

ST Chettri et $\mathrm{al}^{2}$ studied 40 patients who underwent bipolary cautery and classical dissection tonsillectomy on each side of tonsil and reported mean time of operation for electrocautery and cold dissection was $12.04 \mathrm{~min}$ and 16.57 minutes.

Ancy Anthony et $\mathrm{al}^{3}$ study is based on analysis of 40 patients aged 5-40years and reported significant difference in operative time in both methods 15.45 min on electrocautery side versus 18.03 min on cold dissection and snare.

Muneeb Ahmed et $\mathrm{al}^{4}$ study included four year retrospective study done on 200 patients and reported average operative time was 15.7 minutes with cautery and 26.9 minutes for dissection.

Rajeshchaudery et $\mathrm{al}^{5}$ study included 50 children and found out the mean time of operation for electrocautery and cold dissection was $11.1 \mathrm{~min}$ and $18.11 \mathrm{~min}$. 
Mohamed sharif et $\mathrm{al}^{7}$ studied 200 cases of tonsillectomy age between 5 to 40 years and reported the average time of $8 \mathrm{~min}$ on one side of tonsil with bipolar diathermy and 17 min on other side of the tonsil.

Shahid Ali shah et $\mathrm{al}^{8}$ studied 246 patients age ranged from 2 to 46 years $80 \%$ of these was children found time taken by bipolar diathermy ranged from 10 to 20 minutes.

Bipolar electrocautery tonsillectomy focused on simultaneous removal of the tonsils with attainment of hemostasis. But dissection, snare and ligation tonsillectomy was performed in two stages. Firstly, snaring and removal of the tonsils and secondly attaining hemostasis with silk ligatures. This accounted for increased intraoperative blood loss, increased operative time by dissection, snare and ligation method.

\section{Intra Operative Blood Loss}

The mean intraoperative blood loss for dissection and snare method was $59.60 \pm 14.02 \mathrm{ml}$ and for bipolar diathermy method, the mean intra operative blood loss was $39.36 \pm 6.39 \mathrm{ml}$. This shows that the amount of blood loss in bipolar diathermy group (Group B) was lesser than the intra operative blood loss in dissection and snare (Group A). The $\mathrm{p}$ value was $<0.001$. This is statistically significant. Our study was comparable to studies by

Guclu kaan Beriat et al $^{1}$ found out the mean intraoperative blood loss was $22.84 \mathrm{ml}$ for bipolar electro cautery and 113.87 in conventional tonsillectomy.

ST Chettri et $\mathrm{al}^{2}$ found the average amount of bleeding on electrocautery side was $4.07 \mathrm{ml}$ and on the cold dissection side was $14.58 \mathrm{ml}$.

Ancy Anthony et $\mathrm{al}^{3}$ found out that the blood loss was significantly less with the bipolar electro dissection method averaging $47.13 \mathrm{ml}$ compared to $52.23 \mathrm{ml}$ in cold dissection tonsillectomy.

Muneeb Ahmed et $\mathrm{al}^{4}$ found out the average intraoperative blood loss was $10 \mathrm{ml}$ with cautery and $65 \mathrm{ml}$ with dissection method.
Rajesh Chaudhary et $\mathrm{al}^{5}$ found the average amount of bleeding on electrocautery side was $37.2 \mathrm{ml}$ and on the cold dissection was $83.7 \mathrm{ml}$.

Mohamed Sharif et $\mathrm{al}^{7}$ found out the average intraoperative blood loss with diathermy was $14 \mathrm{ml}$ as compared to $42.5 \mathrm{ml}$ by dissection and snare method.

Shahid Ali Shah et al ${ }^{8}$ studied 230 patients undergoing bipolar diathermy tonsillectomy and found out blood loss of 2 to $5 \mathrm{ml}$. Our result was also consistent with reports of Leinbach $\mathrm{RF}^{11}$, Kirzali $\mathrm{T}^{12}$, Mann DG et $\mathrm{al}^{13}$; Carmody D et $\mathrm{al}^{14}$, Hansen JE et al and ${ }^{15}$ Wexler $\mathrm{DB}^{16}$.

Intra operative blood loss during tonsillectomy is one of the major concerns for any otolaryngologist. There is a general agreement that primary bleeding is related to surgical technique $^{31}$. The precise nature of bipolar diathermy dissection allows the blood vessels to be identified and cauterized to keep blood loss to minimal. During bipolar electrocautery dissection, the heat is used to denature the protein of the vessel wall, there by coagulating and sealing the vessel $^{17,18}$.

\section{Post Operative Pain}

The post operative pain assessed using VAS showed that the pain was more in the Bipolar Group (Group B) from Day 0 to Day 5.It has statistically significant $\mathrm{P}$ value $<0.001$. However, There was not much difference in post operative pain in the 2 groups on Day6, Day7 \& Day14.

ST Chettri et $\mathrm{al}^{2}$ reported that on the second post operative day, $35 \%$ of the patients complained of pain on the cauterized side, $30 \%$ complained of more pain on the dissection side while $35 \%$ experienced equal pain on both sides.

Ancy Anthony et al ${ }^{3}$ reported there was no significant difference in post operative pain on the first postoperative day in the diathermy group compared with cold dissection group $(17.5 \%$ versus $10 \%)(\mathrm{p}>0.05)$.

Muneeb ahmed et $\mathrm{al}^{4}$ reported the incidence of post operative pain is significant after 
electrocautery but is not as severe after dissection method.

Rajesh kumar Choudhary et $\mathrm{al}^{5}$ reported on the second post operative day, $38 \%$ of the patients had pain on the cauterized side, $28 \%$ complained more pain on the dissection side while $34 \%$ experienced equal pain on both sides.

Pain, particularly in children is probably the most significant obstacle to recovery following tonsillectomy, influencing the ability to return to normal activity. Some studies state that the tonsil bed healed later in patients undergoing bipolar dissection tonsillectomy, Hence the increase in post operative pain in patients undergoing bipolar dissection tonsillectomy.

\section{Post Operative Complications}

In our study we encountered 1 primary (4\%) haemorrhage in the dissection and snare method and none on bipolar diathermy method.

There were 1 secondary (4\%) haemorrhage in dissection and snare method and 4 secondary haemorrhage $(16 \%)$ in bipolar diathermy.

The incidence of secondary haemorrhage was more in bipolar diathermy method compared to dissection and snare method, However it was statistically not significant $P$ value 0.236 .

Guclu kaan beriat et $\mathrm{al}^{1}$ reported post operative bleeding occurred only in one patient on post operative day 3 in the conventional dissection group, while it occurred in 2 patients on day 5 and day 7 in bipolar group.

Ancy Anthony et $\mathrm{al}^{3}$ reported one case of secondary hemorrhage in bipolar diathermy method which settled with conservative management.

Zafar Iqbal et al ${ }^{6}$ studied 300 patients and reported 8 secondary haemorrhage 3 in dissection and snare group and 5 in bipolar diathermy group.

Mohamed sharif ${ }^{7}$ studied 200 cases and reported both the method had I secondary haemorrhage which was managed conservatively.

Shahid ali khan et al ${ }^{8}$ studied 238 patients who had undergone bipolar diathermy and reported 9 cases of secondary haemorrhage and was managed conservatively without any surgical intervention.

In our study all the 5 patients with secondary haemorrhage underwent conservative treatment and were successfully managed.

\section{Conclusion}

Bipolar electrocautery tonsillectomy is a favourable technique in view of ease of the procedure, lesser operative time and less intraoperative blood loss. However there is increased post operative pain and increased risk of secondary haemorrhage in bipolar electrocautery tonsillectomy. Although there is more intraoperative blood loss, thereby increasing the operative time in dissection and snare tonsillectomy, it is a time tested technique with less post operative pain and morbidity, hence more acceptable to the patient. We conclude that surgeons, Judiciously use both the techniques while performing tonsillectomy.

\section{References}

1. Guclu Kaan Beriat et al: The Use of Bipolar Electrocautery Tonsillectomy in Patients with Pediatric Respiratory Tract Obstruction J Clin Anal Med 2012;3(1):36-40

2. ST Chettri et al; A single blind controlled study comparing bipolar elecrocautery tonsillectomy to cold dissection method in pediatric age groups Chettri el al Elecrocautery tonsillectomy Health Renaissance 2013;11(3): 270-272

3. Ancy Anthony Vithayathil et al.: Comparison between Cold Dissection Snare Method and Bipolar Electrodissection Method in Tonsillectomy Research in Otolaryngology 2017, 6(2): 17-22 DOI:

10.5923/j.otolaryn.20170602.01

4. Muneeb Ahmed et al: A Comparison of Dissection-method and Diathermy Tonsillectomies JPMA 50:215, 2000. 
5. Rajesh Kumar Choudhary et al: A Comparison Between Dissection-Method And Diathermy Tonsillectomies in Rims, Ranchi IOSR Journal of Dental and Medical Sciences (IOSR-JDMS) e-ISSN: 2279-0853, p-ISSN: 2279-0861.Volume 16, Issue 1 Ver. X (January. 2017), PP 4547

6. Zafar Iqbal, Mohammad Zafar Rabbani, Muhammad Jawad Zafar Rawal Post Tonsillectomy Hemorrhage Incidence, a Comparison between Dissection and Bipolar Diathermy Techniques Med J 2009;34:23-25.

7. Mohammad Sharif et al: Diathermy Tonsillectomy Versus Conventional Dissection Tonsillectomy JPIM Vol. 15 (1) 84-90.

8. Shahid Ali Shah et al: Evaluation of Safety of Bipolar Diathermy Tonsillectomy $\mathbf{J}$ Ayub Med Coll Abbottabad 2007;19(4)

9. Fozia Wani et al: Redefining indications and evaluation of dissection versus diathermy method of tonsillectomy International Journal of Research in Medical Sciences. Int J Res Med Sci. 2013 Nov;1(4):501-514

10. Desmond A Nunez et al; Post Operative Tonsillectomy Pain in Pediatric Patients Arch Otolaryngol Head Neck Surg.2000;126:837-841.

11. Leinbach RF, Markwell SJ, Colliver JA, Lin SY. Hot versus cold tonsillectomy: A systematic review of the literature. Otolaryngology - Head and Neck Surgery 2003; 129 (4): 360-64.

12. Kirazli $\mathrm{T}$ et al. Bipolar electrodissection tonsillectomy in children. Eur Arch Otorhinolaryngol 2005; 262: 716-18.
13. Mann DG et al. Tonsillectomy - Some like it hot. Laryngoscope 1984; 94: 677-9.

14. Carmody D, Vamadevan T, Cooper SM post-tonsillectomy hemorrhage. J Laryngol otol.1982; 96:635-8Kousha A, Bana R, Fotoochi $\mathrm{N}$ and Banan R. cold dissection versus bipolar electrocautery tonsillectomy. Journal of Research in Medical Sciences 2007; 12(3): 117-20.

15. Hansen JE.A technique for improved tonsil and adenoid surgery. Ear Nose \&Throat Journal 1979; 58:11-23.

16. Welxer DB.Recovery after tonsillectomy. Electrodissection versus sharp dissection techniques. Otolaryngol head neck surgery 1996;114:576-81.

17. Pang YT. Paediatric tonsillectomy: bipolar electro dissection and dissection / snare compared. J Laryngol Otol 1995; 109: 733-6.

18. Murthy P,Laing MR. Dissection tonsillectomy: Pattern of post operative pain, medication and resumption of normal activity.J Laryngol Otol 1998;112:41-4. 